\title{
MULHERES QUE “BOTAM BANCA": GÊNERO E TRABALHO EM SANTARÉM/PA
}

\author{
Marla Elizabeth Almeida Reis ${ }^{1}$ \\ Raquel Wiggers ${ }^{2}$
}

\section{Introdução}

Nas etnografias é comum que o trabalho e a esfera econômica apareçam diluídos em meio aos outros aspectos da vida social do grupo. Por vezes sob a forma de categorias como: dom, dádiva, reciprocidade, troca, capital simbólico, ajuda e tantos outros termos vinculados a contextos de trabalho em sociedades diversas.

A pesquisa que originou esse artigo ocorreu na cidade de Santarém, situada na região norte do Brasil, Oeste do Pará, na margem direita do rio Tapajós na sua confluência com o rio Amazonas. A população local é de 294.580 habitantes, de acordo com o censo demográfico de 2010, realizado pelo IBGE.

A população economicamente ativa na cidade é de 101.663 pessoas, sendo 37.464 mulheres, e destas, 12.121 estão inseridas no setor informal. A parcela da população feminina trabalhando na informalidade se torna evidente devido aos diversos pontos comerciais alocados em residências, seja em um cômodo da casa reservado para a atividade ou ao entorno da casa.

Como bem observa Delma Neves, ao analisar o município de Santarém, as mulheres "estão integradas a redes de produção e de comercialização nos espaços citadinos, planalto e ribeirinhos, enfim, às redes que conectam à produção em setores agrícolas e artesanais, comerciais e de serviços”. (NEVES, 2014: 19)

Dentre as atividades que funcionam nas residências destacam-se: serviços de cabelereiras, manicures, costureiras, pequenas tabernas e venda de artesanatos. Encontra-se também diversos tipos de venda de alimentos como pequenas lanchonetes, vendedores ambulantes, delivery de comida, encomenda de doces e salgados, e bancas de comida.

\footnotetext{
${ }^{1}$ Universidade Federal do Amazonas, Brasil. Email: marla-reis@hotmail.com ORCID id: https://orcid.org/0000-0002-9785-2909

${ }^{2}$ Universidade Federal do Amazonas, Brasil. Email: raqwiggers@gmail.com ORCID id: https://orcid.org/0000-0001-9900-8595
} 
Apesar das várias modalidades de venda de comida e prestação de serviços desenvolvidos por mulheres em Santarém, neste trabalho tomarei como objeto central de análise as mulheres que "botam banca". O termo "botar banca" é uma categoria analítica que remete ao ato de vender comida em cima de uma mesa, geralmente de madeira, localizada à frente ou no entorno da residência das vendedoras.

Dentre as comidas presentes nas bancas estão: salgados, bolos, pudim, salada de fruta, churrasco, sucos, vatapá, tacacá e mungunzá. As mulheres decidem quais comidas serão vendidas e quais os dias e horários de funcionamento, mas em geral as bancas são vistas pela cidade no período da tarde, a partir das 15 horas e algumas permanecem abertas até as 22 horas, a depender da clientela.

Figura 1 - Banca de comida em Santarém/Pa

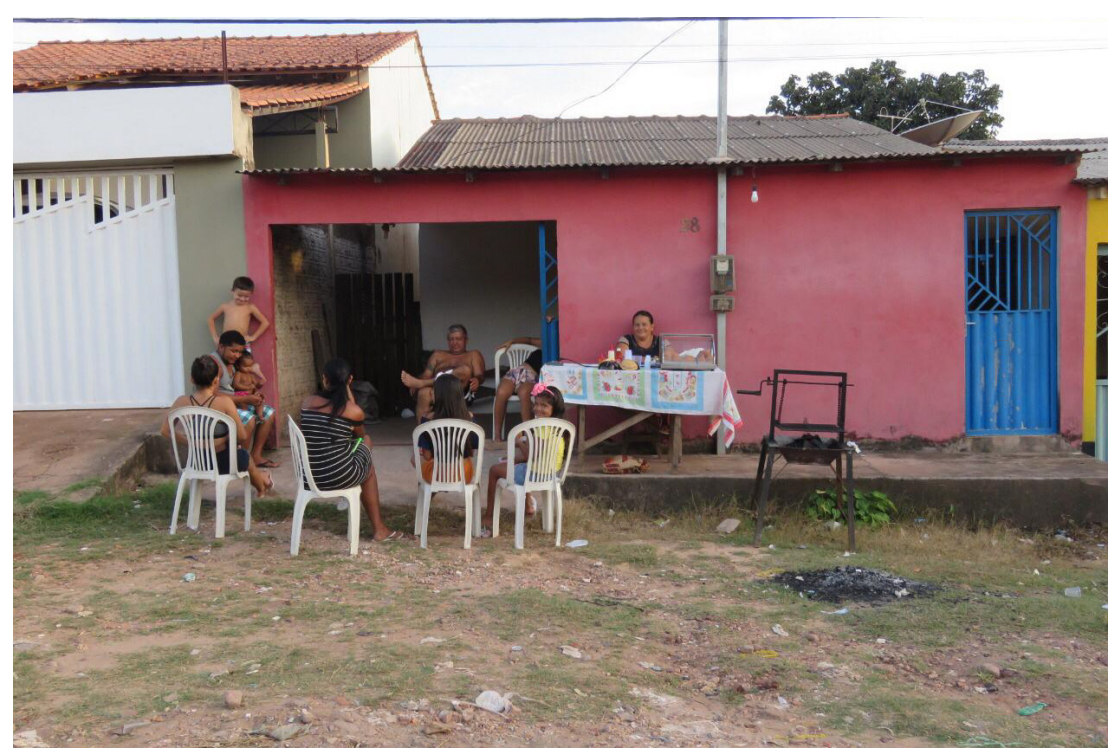

Autora, 2019.

No presente trabalho procuro compreender, a partir da análise da trajetória das interlocutoras, quem são as mulheres que "botam banca", como ocorreu o processo de transmissão dos saberes necessários ao desenvolvimento da atividade, quais foram os motivos que levaram elas a desenvolver esse trabalho e quais são as lógicas econômicas utilizadas na manutenção da atividade.

O trabalho de campo ocorreu entre os anos de 2012 e 2019 nos seguintes bairros: Livramento, Interventoria, Santana e São José Operário, alguns dos bairros que outrora 


\section{Mulheres que "Botam Banca": Gênero e trabalho em Santarém/PA}

compunham a área da Grande Prainha. Em 2018 a cidade deixou de ser dividida por grandes áreas e passou a ser dividida em zonas, atualmente esses bairros fazem parte da Zona Leste da cidade. Apesar da pesquisa estar delimitada geograficamente, tal atividade econômica é expressiva e ocorre por toda a cidade.

Para a obtenção de dados foi realizado o método de observação participante com mulheres que botam bancas onde acompanhei a rotina e o momento de trabalho das interlocutoras, também foi realizado aplicação de questionários, registro fotográfico, diário de campo, entrevistas abertas e conversas informais com 22 mulheres que "botam banca" em Santarém.

Aproximo-me teoricamente da perspectiva de Fonseca (1999) de que a filosofia de “cada caso é um caso" e o método etnográfico não são equivalentes. Mais do que descrições individuais, a etnografia busca compreender aspectos coletivos da vida social. Para tanto início apresentando a história de Maria, pois trata-se de um caso exemplar que ilustra a trajetória das outras interlocutoras.

\section{Trajetória em narrativa}

Maria, 45 anos, casada, nasceu na região do Lago Grande, interior de Santarém. Aprendeu a cozinhar na infância, observando a mãe, e passou a ajudar em casa "desde cedo", ao cuidar dos irmãos mais jovens e realizar pequenas tarefas. O seu primeiro trabalho "remunerado" foi aos 17 anos como doméstica, quando foi enviada para Santarém para morar em casa de família e completar os seus estudos na cidade. Lá ela aprendeu a fazer "comidas mais gostosas, aprendi muito porque todo dia eu fazia, aí fui ganhando experiência, aprendendo a cozinhar mais rápido, fazer mais receitas”.

Morar e trabalhar em casa de família não foi uma experiência agradável para Maria, ela trabalhava o dia inteiro e quase não tinha tempo para estudar. Acerca disso ela recorda que: "trabalhava que nem escrava e eu ficava tão cansada que não conseguia estudar, mas eu tinha que estudar pelo menos um pouquinho para minha mãe ficar feliz, sabe?".

Maria raramente recebia em dinheiro, mas a família que lhe abrigava sempre lhe fornecia o material escolar necessário, como livros, cadernos e vales de ônibus. Em adição a isto, davam-lhe roupa, sapatos e comida. As roupas e calçados geralmente eram 
usados, e quanto à comida, Maria servia toda a família e só depois podia comer o que sobrasse. Nem tudo o que os patrões compravam poderia ser consumido por ela, geralmente "comidas gostosas" como salgados, doces, bolachas, iogurte, dentre outros, eram dos filhos ou do casal. Apesar disso, quando iam apresentar ela para outras pessoas, diziam que ela era "praticamente da família", como forma de afirmar se tratar de laços de afetividade/parentesco e não empregatícios.

Aos poucos, tal relação de trabalho ficou insustentável. Maria percebeu que naquelas condições não poderia obter independência nem melhorar de vida. Também notou que não conseguiria estudar e dar conta de todas as tarefas que tinha para fazer na casa dos patrões. Assim, o casamento surgiu como uma alternativa viável para que ela constituísse a sua própria família e deixasse de se sujeitar à relação de trabalho não remunerado na qual estava vivendo.

O pretendente de Maria estudava junto com ela, em suas palavras: "ele era um moço calmo, trabalhador e gostava de mim". Ao estabelecer a relação conjugal, eles foram morar nos fundos da casa da família do esposo, segundo ela: "no início era só um puxadinho, sabe? Mas aí a gente foi arrumando! Hoje a minha casa é bonita!”. O marido continuou a realizar serviços gerais, enquanto ela começou a trabalhar no centro comercial da cidade como atendente em uma loja de roupas. Esse emprego durou até o nascimento do primeiro filho, quando ela passou a ficar "só em casa".

Uma gestação seguiu a outra, até Maria ter os seus três filhos. Como as crianças ainda eram pequenas, ela não podia trabalhar "fora de casa", mas ao mesmo tempo sentia vontade de ter algum rendimento. Foi dessa necessidade que surgiu a ideia de "botar banca". Para iniciar a atividade ela pediu dinheiro ao marido e economizou até ter o suficiente, então comprou os ingredientes e começou a fazer as comidas. No início ela só fazia vatapá, tacacá, bolo e suco, depois de um tempo acrescentou à banca pudim, salgados e salada de frutas. Maria "bota banca" na sexta-feira, sábado e domingo, das 16 horas até as 20 horas, em frente à sua casa.

\section{As mulheres que botam banca}




\section{Mulheres que "Botam Banca": Gênero e trabalho em Santarém/PA}

Antes de migrar para a cidade de Santarém, muitas das interlocutoras moravam com suas famílias em roças e viviam do plantio e/ou da criação de poucas cabeças de gado. Ainda na infância tais mulheres oscilavam entre "ajudar" os homens da família no roçado, e "ajudar" as mulheres nas atividades domésticas.

Os principais trabalhos desenvolvidos no ambiente doméstico são: o cuidado com os irmãos mais novos ou idosos, preparação dos alimentos, lavagem das roupas, costura, limpeza da casa e da área da casa (ajuntar as folhas que caem no quintal, varrer o "terreiro", tirar as plantas daninhas que crescem na frente da casa etc.)

As mulheres aprenderam a cozinhar na infância, por volta dos 10 anos, com as suas mães, avós e outras mulheres. Isso pode ser visto na fala de Rosa: "Eu aprendi desde sempre, porque desde menina eu ajudava a minha mãe e fui aprendendo a fazer a carne, o baião, tudo". (Rosa, 28/05/2013).

A migração para a cidade de Santarém pode ser motivada pelas dificuldades da família em se manter no campo, necessidade em acessar o sistema de saúde, busca por postos de trabalho ou para a conclusão dos estudos. Contudo, conforme observei em pesquisa anterior, que existe também grande curiosidade por parte das moças em conhecer a cidade, pessoas, dinâmicas e modos de vida dos espaços citadinos. (REIS, 2019:229)

Algumas mulheres chegam à cidade juntamente com a família, em outros casos família permanece no interior e envia as filhas jovens para a cidade com o intuito de estudar e trabalhar em casa de família, como foi o caso de Maria, narrado anteriormente.

Já na cidade, grande parte das interlocutoras desenvolve ofícios de cozinheiras, empregadas domésticas, lavadeiras, babás, cuidadoras e vendedoras em lojas no centro da cidade. Após o nascimento dos filhos torna-se difícil a permanência das mulheres no mercado de trabalho, pois, os seus vínculos empregatícios se davam por vias informais e não lhes conferiam direitos trabalhistas como licença maternidade, por exemplo. E “além disso, serviços de creches não são de fácil acesso e grande parte das mulheres demonstra receio de deixar os filhos sob os cuidados de terceiros." (REIS, 2019:230)

Neste contexto, as mulheres encontram no "botar banca" um trabalho possível, pois trata-se de um ofício que pode ser desenvolvido na residência, permite um horário de trabalho mais flexível, não necessita de grande investimento financeiro para iniciar e 
as mulheres acionam um conhecimento que já possuem. Em pesquisa anterior observei que:

O "botar banca" surge como uma dessas atividades, que permite às mulheres assegurar obtenção de rendimentos fundamentais ao sentimento de autonomia familiar, e negociar a simultaneidade do uso dos tempos dedicados às duas atividades, trabalho e cuidado com a família. Assim, o fato de trabalhar na própria casa permite a essas mulheres administrar o tempo de trabalho de modo a atender tanto as necessidades familiares quanto a atividade econômica, podendo então interromper o serviço doméstico para levar os filhos para a escola ou médico, podem cozinhar e cuidar dos filhos pequenos ou limpar a casa. (Reis, 2016:20)

Algumas mulheres iniciam a atividade econômica para ajudar a custear a educação dos filhos, para sanar uma dívida, comprar determinado objeto ou complementar o rendimento familiar.

Juntamente com a venda de comida, as mulheres conjugam outras formas de trabalho, como, por exemplo, vender produtos de catálogos; vender artesanato; vender cartela de prêmios ou rifas; costurar ou remendar roupas; vender galinhas, patos ou porcos que elas criam no quintal da casa etc.

Percebi que não havia grande preocupação por parte das entrevistadas em nomear o tipo de trabalho que desenvolviam. Quando questionadas sobre assunto, era comum respostas como: "eu trabalho com isso, vendendo comida na banca" ou "meu trabalho é esse, botar essa banca para fora, vender comida e depois colocar a banca para dentro". Isso revela que as mulheres não estão preocupadas em dar nome ao trabalho que desenvolvem, uma vez que realizam diferentes atividades econômicas simultaneamente. Dessa forma, pode-se definir analiticamente o "botar banca" como:

1) ser uma atividade econômica de característica informal, desenvolvida por mulheres que vendem comida; 2) a venda de comida ocorre em cima de mesas de madeira, colocadas na calçada, próximo a residência das vendedoras; 3) há variedade de comidas, e não lhe é outorgada a especialização de um prato, como por exemplo ocorre com as tacacazeiras ou vendedoras de acarajé; 4) Em geral, além da venda da comida, a mulher desenvolve outras atividades econômicas como: venda de produtos por catálogos, venda de rifas de sorteios, venda de animais de pequeno porte, crochê, tricô etc. (Reis, 2019:228)

As mulheres que "botam banca" no período da tarde, privilegiam comidas como vatapá, tacacá, salgados, bolo, pudim, mugunzá e sucos. Tais alimentos são caracterizados pelas vendedoras e consumidores como lanches. Já nas bancas que 


\section{Mulheres que "Botam Banca": Gênero e trabalho em Santarém/PA}

funcionam no período da noite é comum a venda de vatapá, tacacá, sucos, churrasco completo ou churrasquinhos. Tais artigos são caracterizados como jantar.

Os dias e horários de funcionamento das bancas variam de acordo com o movimento, dado que podem abrir o negócio mais tarde, fechar mais cedo ou mesmo não abrir. Como pode ser visto na fala a seguir: "Aqui eu trabalho de tardezinha, mas depende é do movimento, se eu ver que tá movimentada aqui, aí abro mais cedo, se o movimento continuar bom eu fecho mais tarde, mas se for ruim, aí eu fecho é cedo! Tem dia que eu nem venho aqui!" (Delzanita, 23/06/2014).

Em seu livro “A Casa e a Rua” (1997), Roberto da Matta levanta a reflexão de que "o tempo e o espaço constroem e, ao mesmo tempo, são construídos pela sociedade". Isso fica bem ilustrado no livro "Os Nuer" (1999), de Evans-Pritchard, onde este grupo tribal do Sudão organiza o tempo a partir das condições ecológicas, como o dia, noite, cheia e seca; as atividades sociais vinculadas a locais específicos. Para se referir ao passado eles fazem referência a parentes mais velhos ou grupos etários, "como, por exemplo: 'isso aconteceu no tempo em que meu Geti (avô) era moço. . .." (Damatta, 1997:33). O mesmo autor também cita exemplos de sociedades que contam o tempo por preces ou atos naturais:

Assim, no Chile do século XVII, o tempo de um terremoto foi medido com precisão: ele teve a duração de dois credos! E na Inglaterra, antes que a 'revolução individualista e puritana' tomasse corpo e ganhasse hegemonia, o tempo podia ser medido como o 'tempo de um padre-nosso' e até mesmo como o 'tempo de uma mijada'." (Damatta, 1997:36)

Para esse autor, a sociedade brasileira se singularizava pelo fato de ter muitos espaços e muitas temporalidades que conviviam simultaneamente. Isso é perceptível na fala das mulheres, pois sempre que perguntava a elas sobre as suas rotinas surgiam expressões como: "bem cedo", "ao entardecer", "de noitinha", "antes do almoço", "depois do almoço", "quando as crianças vão para a escola", "durante a novela", "de vez em quando". Poucas mulheres se referiam ao tempo como "horas". Ao rememorar, as mulheres costumam usar expressões como "quando eu era bem pequena", "quando eu morava na roça" e "faz muito tempo" para se referir à idade e a eventos passados.

Eu que tenho que acordar cedo pra ir na feira comprar os materiais e depois tenho que fazer as comidas, manter elas quentes, de vez em quando eu tenho que ir esquentar o tacacá e o vatapá. (Sara, 04/06/2011) 
Observei que para estas mulheres, o tempo é percebido mais pelas etapas do sol, locais e pelas atividades vinculadas àquele horário do que pelas marcações em horas do relógio. Não estou dizendo que essas mulheres negam a contagem do tempo em horas, mas estou chamando a atenção para a coexistência de formas paralelas de percepção de tempo, o que contraria a lógica do capitalismo onde o tempo e o espaço tem "medidas únicas, coordenadas num sistema também oficial e universal de medidas, fazendo parte de uma ideologia igualmente dominante" (Matta, R. 1997:35).

Essa coexistência é muito diferente de um sistema onde as temporalidades tendem a ser todas ordenadas pelos mesmos eixos de classificação, sistemas onde o relógio tende a dominar todos os tempos.

\section{4. "Um dinheirinho a mais": as lógicas econômicas das mulheres que botam banca}

De acordo com Carvalho (1981), embora as lógicas econômicas do sistema capitalista sejam predominantes na atualidade, elas não representam uma racionalidade universal, pois não são as únicas possíveis ou eficazes.

No que concerne aos sistemas econômicos, diversas etnografias destacam exemplos de grupos que não visam a maximização da produção, mas se baseiam em relações sociais, de prestígio, parentesco etc. Segundo Carvalho (1981:8):

Aos poucos o objeto da antropologia econômica passa a se definir como análise comparada de todos os sistemas reais e possíveis. Afastado das concepções formalistas, que pretendiam a universalidade do comportamento econômico e do substantivismo empirista de K. Polanyi, G. Dalton e outros, o econômico ganhava nova significação não só porque se define como produção, repartição e consumo de bens materiais, mas como domínio de atividades particulares e aspectos articular de todas as atividades humanas que constituem a totalidade da vida social.

O modelo econômico capitalista, apesar de ser predominante, não é o único existente, pois existem sociedades ao redor do mundo que possuem lógicas econômicas distintas. Um exemplo disso são as mulheres que "colocam banca". Estas não seguem regras rígidas de mercado ou cálculos específicos de produção, típicos de uma economia 


\section{Mulheres que "Botam Banca": Gênero e trabalho em Santarém/PA}

capitalista, mas se valem de outros cálculos para manter os seus rendimentos. Conforme pode ser visto na fala a seguir:

Eu penso assim: a goma é cara, o camarão é caro. Eu vejo o preço desses ingredientes, aí eu vejo quanto fica pra eu comprar todos os materiais pra fazer o tacacá e quanto eu vou ter que vender pra conseguir o dinheiro dos materiais de volta e mais um dinheirinho pra mim. (Antônia, 05/12/2014)

Para saber como atribuir valor ao seu produto, Antônia soma o custo total dos ingredientes e divide pelo tanto de produtos que ela precisa vender para conseguir o dinheiro investido de volta. Depois disso, acrescenta um "dinheirinho" a mais, para que ela consiga um valor um pouco maior do que foi investido.

Ao atribuírem valor ao produto, as mulheres não consideram todos os custos para a fabricação dos alimentos. Nesta seara, a água utilizada em todo o processo, a energia elétrica, o valor gasto com o deslocamento até a feira ou supermercado e a força de trabalho delas não são contabilizados.

A mulher que vai à feira comprar ingredientes para o preparo das comidas que serão servidas na banca compra também ingredientes que serão servidos nas refeições familiares. Do mesmo modo que em algumas situações o arroz da casa é feito com o arroz que será servido na banca, ou a família pode almoçar o vatapá que sobrou da banca do dia anterior.

Devido à permeabilidade entre os produtos destinados à atividade econômica e os produtos destinados ao consumo doméstico, essas mulheres têm muita dificuldade em calcular com exatidão os fatores produtivos. Isso pode ser visto na fala a seguir: " $\mathrm{O}$ meu pai que vai comprar as coisas no açougue e ele já traz o almoço também” (Sara, 04/06/2011).

De acordo com Chayanov (1981), para obter a lucratividade econômica é necessário calcular a receita bruta (todo o valor arrecadado com a atividade) menos os custos (compra dos materiais, transporte, energia, pagamento de funcionários, impostos, força de trabalho etc.). E o resultado disto tem que ser maior do que todo o capital investido, levando em consideração a taxa de juros predominante no país. Segundo o mesmo autor:

A teoria econômica da sociedade capitalista é um complexo sistema de categorias econômicas inseparavelmente vinculadas entre si: preço, capital, salários, juros, renda, determinam-se uns aos outros, e são fundamentalmente interdependentes. $\mathrm{Na}$ ausência de qualquer destas categorias econômicas, todas as demais perdem o seu 
caráter específico e seu conteúdo conceitual, e nem sequer podem ser definidas quantitativamente. (Chayanov, 1981:136)

Podemos observar que o conteúdo teórico de algumas categorias como renda, lucro, salário, que são típicas do sistema de produção capitalista, não podem ser aplicados na forma econômica das mulheres que "colocam banca", o que faz com que outras categorias de nosso sistema econômico, que são conceitualmente vinculadas, desapareçam também.

Embora as mulheres que "botam banca" estejam inseridas em uma sociedade capitalista, elas não estão apoiadas nos princípios e regras da economia capitalista, uma vez que as mulheres não seguem as regras rígidas de mercado ou cálculos específicos de produção, mas elas se valem de outros cálculos para manter os seus rendimentos.

As sobras também não contabilizadas, estas podem ser de vários tipos. Existem as sobras que ficam no prato do freguês, estas podem ser jogadas fora ou utilizadas para alimentar os animais da família, sejam gatos cachorros, galinhas, patos ou porcos.

Como se trata de famílias pobres, que em sua maioria vieram de zonas rurais de Santarém e se instalaram em bairros periféricos, essas pessoas, apesar de "estarem na cidade", ainda mantêm características camponesas como, por exemplo, a criação de animais de pequeno porte no quintal da casa ou o cultivo de pequenas hortas.

A criação ou cultivo no quintal da casa, conciliados com o "botar banca", criam um movimento de "ida" e "volta" dos recursos e sobras. Neste sentido, os animais e plantas que são criados no quintal são vendidos ou consumidos pelo grupo doméstico, e também podem servir para a preparação das comidas que serão servidas na banca em frente à residência.

Em contrapartida, as sobras das comidas que ficam nos pratos dos clientes podem ser utilizadas para alimentar os animais criados no quintal ou, em alguns casos, como as cascas das frutas, podem ser usadas para fertilizar o solo onde está localizada a horta. Como pode ser exemplificado no esquema abaixo:

Figura 2 - Movimento de ida e volta das sobras. 


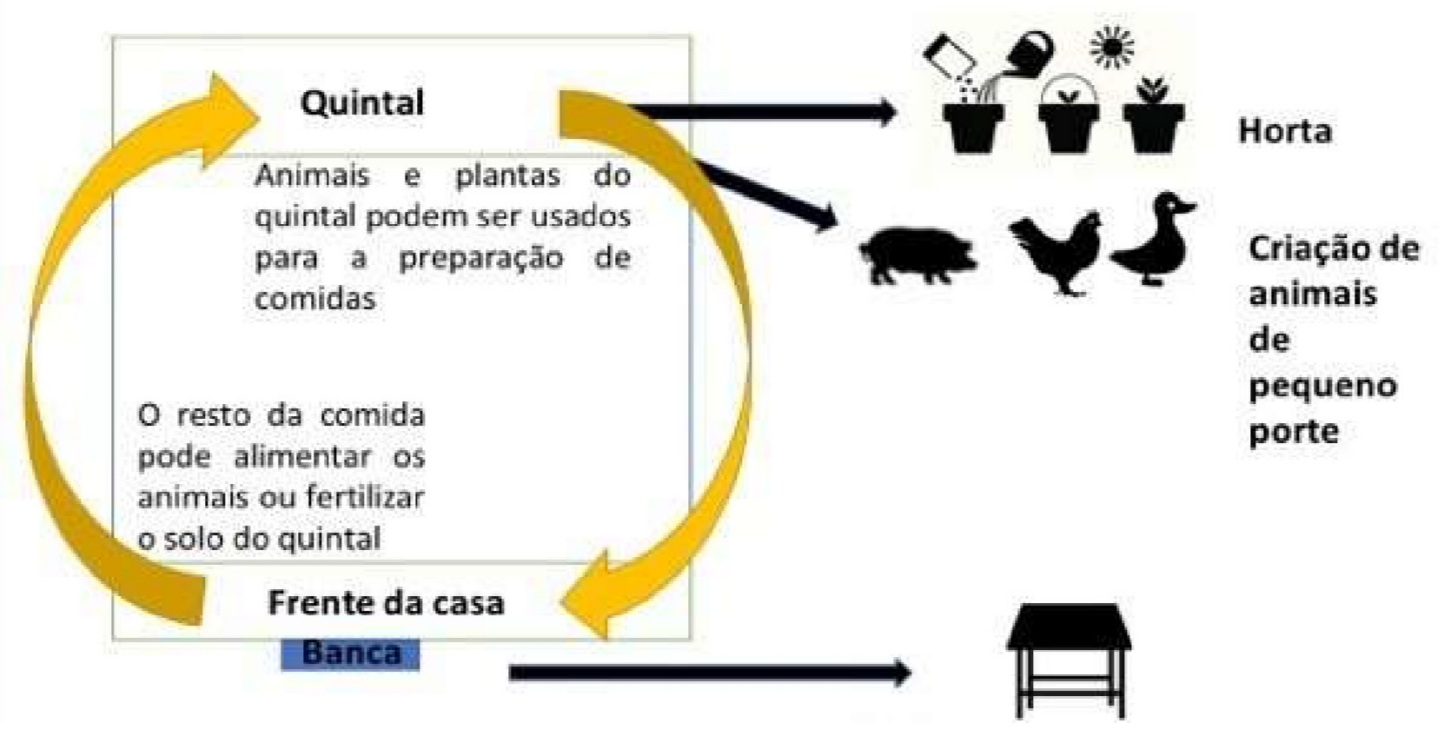

Autora, 2018.

Ademais desta forma de utilização das sobras, é importante ressaltar a existência de um outro tipo de sobra, sendo estas as comidas que não são vendidas no mesmo dia. Nestes casos, os alimentos não vendidos podem ser consumidos pela família no mesmo dia ou como almoço do dia seguinte. Dessa forma, grande parte das sobras é incorporada pela família, reduzindo a quantidade de restos descartados pela impossibilidade de ser aproveitados.

Assim, compreende-se que as esferas do doméstico e do econômico são permeáveis, o que dificulta quantificar com exatidão os fatores necessários para a produção das comidas do "botar banca". Apesar disso, as mulheres que "botam banca" possuem formas eficientes de contabilizar e otimizar os seus rendimentos, através do movimento de incorporação das sobras que são usadas para diversos fins, como fertilizar o solo e alimentar os animais.

Apesar de cada prato ter valor e quantidade pré-definidos, em alguns casos essas medidas podem ser adequadas ao gosto do cliente, de modo que a mulher pode colocar um pouco mais ou um pouco menos, dar um desconto, ou negociar com o cliente, o que também dificulta a precisão na hora de contabilizar as entradas e saídas.

Para o tacacá eu coloco três conchas de tucupi e uma de goma, duas colheres de jambu e uns 7 camarões, mas se o cliente quiser eu posso colocar mais ou menos 
goma, posso misturar o tucupi doce e o azedo. Tem gente que não gosta de tucupi muito quente, aí eu não deixo ferver, deixo só meio morno. . . (Rosa, 13/03/2014)

A fala de Delzanita, 43 anos, dona de uma banca de comidas típicas, ao se referir ao preparo do vatapá, exemplifica como a lógica das interlocutoras é eficaz. Aqui, percebe-se a criatividade e a otimização dos recursos disponíveis no processo de elaboração dessas comidas:

\begin{abstract}
O vatapá de verdade é feito com camarão, mas o camarão é remoso e tem muita gente que não pode comer, fora que ele é bem caro também, por causa disso começaram a fazer o vatapá de frango, que tá dando muito certo. É muito difícil ver vatapá de frango em ponto turístico ou em lugar de gente chique. O vatapá de frango é mais de pessoas pobres. Sempre tem em aniversário, casamento. . . tudo quanto é festa! Porque ele é barato, todo mundo gosta e enche bastante. (Delzanita, 23/06/2014)
\end{abstract}

Na entrevista acima pode-se ver que, segundo Delzanita, a receita tradicional do vatapá, consumida em lugares mais elitizados, é feita com camarão, porém, por conta do alto preço deste ingrediente, ele foi substituído por frango, que é mais barato e "enche mais”, ou seja, é um recurso economicamente viável para famílias mais pobres.

Raramente as mulheres que "botam banca" utilizam anotações para gerir sua atividade econômica, isso só foi visto em dois casos. Em ambos os casos, as anotações estavam confusas e riscadas, mas faziam sentido para as interlocutoras, que se prontificaram a me fornecer uma explicação prolongada para que eu compreendesse a lógica utilizada por elas e escrita no papel.

Na primeira situação, a dona Joana me explicou da seguinte forma: "Eu sou analfabeta, quase analfabeta, sei contar e sei escrever uma coisa ou outra. . . eu uso esse caderno para ter um controle de quanto fiz e de quanto eu vendi, até porque eu já tô velha, vivo esquecendo das coisas". Joana não permitiu que eu tirasse foto do caderno de anotações dela porque diz ter vergonha da letra feia. Por conta disso, fiz uma tabela para demonstrar a racionalidade econômica de Joana:

Tabela 01: Racionalidade Econômica de Joana 


\begin{tabular}{|lllllll|}
\hline Bolo & 05 & 05 & 05 & 05 & 05 & 05 \\
\hline Salgado & 02 & 02 & 02 & 02 & 02 & 02 \\
\hline
\end{tabular}

Autora, 2016.

Joana escreve os produtos que serão vendidos no dia, a quantidade e preço de cada um deles. Por exemplo, em um dia de trabalho joana faz um bolo e o divide em seis fatias, cada fatia será vendida por cinco reais. Então ela escreve no papel 5 reais, seis vezes. Ela faz a mesma coisa com o salgado e as demais comidas. A medida em que vende cada item risca do caderno as fatias ou unidades que foram vendidos, como pode ser exemplificado a seguir:

Tabela 02: Racionalidade Econômica de Joana II

\begin{tabular}{|lcccccc|}
\hline Bolo & 05 & 05 & 05 & 05 & 05 & 05 \\
\hline Salgado & 02 & -02 & 02 & 02 & 02 & 02 \\
\hline
\end{tabular}

Autora, 2016.

No final do dia, por exemplo, Joana saberá que vendeu quatro fatias de bolo por 5 reais e dois salgados por 2 reais. Com essa forma de gerir o seu rendimento, Joana consegue controlar a quantidade de produtos vendidos, sabe ao certo a quantidade de fatias de bolo, cuias de tacacá ou copos de suco. Ela faz isso com todos os pratos que vende em sua banca, e depois anota o valor final do que foi ganho no dia. Ao iniciar um novo dia, ela risca a anotação anterior e escreve em baixo nova tabela, de acordo com o que será vendido naquele dia.

Já dona Rosa anota o produto que foi vendido e o preço recebido. Ao contrário de Joana, essas anotações não são fixas e levam em consideração as negociações com o cliente, como pode ser visto na imagem a seguir: 
Figura 3 - Caderno de anotações da entrevistada

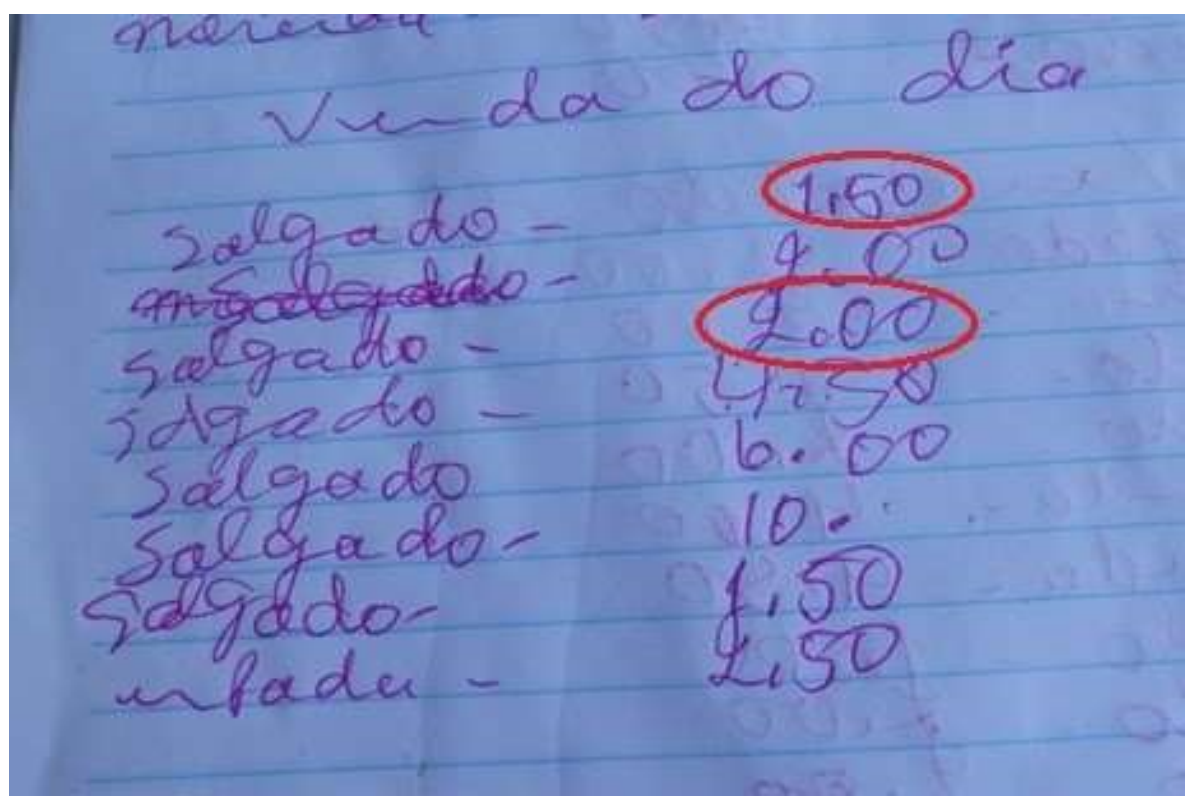

Autora, 2017.

No primeiro caso, circulado em vermelho, o salgado foi comercializado a um real e cinquenta centavos, enquanto no segundo círculo, o salgado foi vendido por dois reais. Isso mostra que existe fluidez na negociação dos preços e que ela consegue passar isso para as suas anotações. Em alguns casos, ao lado do salgado estão escrito valores mais altos, como seis ou dez reais. Isso significa que foi vendido mais de um salgado para a mesma pessoa.

Outra técnica utilizada com frequência pelas mulheres entrevistadas é o uso de envelopes para fazer o controle financeiro mensal. Elas separam alguns envelopes e escrevem neles o nome de contas ou coisas que desejam adquirir, como, por exemplo, aluguel, energia, uma geladeira nova, material escolar para os filhos ou netos, dentre outros. Desta forma, à medida em que ganham dinheiro com a venda da comida, essas mulheres preenchem aos poucos os envelopes, até conseguirem alcançar o valor necessário.

\section{Considerações finais}




\section{Mulheres que "Botam Banca": Gênero e trabalho em Santarém/PA}

O "botar banca" é uma atividade econômica informal de venda de comida muito comum na cidade de Santarém. De acordo com os dados obtidos, observei que a transmissão do oficio ocorre na infância, quando as interlocutoras observam as suas mães na lida diária e ajudam com os trabalhos domésticos.

Posteriormente as mulheres aperfeiçoaram o conhecimento através da prática cotidiana e do aprendizado de novas receitas por meio de programas culinários de rádio e televisão, revistas, embalagens de produtos e conversas com outras mulheres.

$\mathrm{Na}$ vida adulta, após o nascimento dos filhos, quando se torna difícil conciliar o trabalho fora de baixa remuneração e o cuidado da casa, essas mulheres passam a trabalhar nas suas residências e acionam esses conhecimentos como forma de obter um rendimento que é essencial para a autonomia do grupo doméstico.

O "botar banca" é uma atividade econômica, totalmente gerida pelas mulheres, onde elas controlam os dias, horários e as comidas que serão vendidas. O local da banca é mais do que apenas um espaço de venda de alimentos, pois no entorno dele se reúnem vizinhos, amigos, parentes e pessoas que transitam pelo bairro. Essas interações fortalecem as redes de relações sociais entre as pessoas que frequentam tais espaços. Dessa forma é comum ver crianças brincarem ou fazerem atividades escolares no entorno da banca e adultos assistirem televisão e/ou conversarem.

As mulheres que "botam banca" se utilizam de medidas práticas e lógicas próprias para garantir a manutenção da atividade e obtenção de recursos. Assim, a experiência e a rotina da vida doméstica fazem com que as mulheres entrevistadas não precisem de um medidor específico, mas se utilizem de copos, xícaras, colheres e bacias para obter a dosagem certa dos ingredientes.

Da mesma forma ocorre com os cálculos desenvolvidos por essas mulheres para atribuir preço às comidas. Embora sejam diferentes do cálculo capitalista, estes têm se mostrado eficientes, dado que com o dinheiro obtido através do "botar banca" as mulheres conseguem pagar despesas mensais do grupo doméstico e custear pequenos itens de uso pessoal para si ou para seus filhos.

Com o rendimento obtido, as interlocutoras conseguem custear itens de pequeno valor para si, seus filhos e demais familiares, e quando economizam dinheiro, 
conseguem fazer reformas na casa, comprar utensílios domésticos ou aplicar na melhoria do local da banca.

\section{REFERÊNCIAS}

AQUINO, Soraya Farias. Mulher e trabalho informal. Manaus: Instituto Federal de Educação, Ciência e tecnologia do Amazonas, 2010.

ARAÚJO, Angela; LOMBARDI, Maria Rosa. Trabalho Informal, Gênero e Raça no Brasil do início do século XXI. Cadernos de Pesquisa (Fundação Carlos Chagas. Impresso), v. 43: 452- 477, 2013.

BRUSCHINI, Cristina; RICOLDI, Arlene. Revendo estereótipos: o papel dos homens no trabalho doméstico. Revista Estudos Feministas, Florianópolis, v. 20, n. 1, p. 259287, 2012.

CHAYANOV, Alexander. Sobre a teoria dos sistemas econômicos não capitalistas. In: SILVA, José Graziano da; STOLCKE, Verena. A questão agrária. São Paulo: Editora Brasiliense, 1981.

CARVALHO, Edgard de Assis. Godelier: antropologia. São Paulo: Ática, 1981.

DAMATTA, Roberto. A casa \& a rua. $5^{\text {a }}$ edição. Rio de Janeiro: Rocco, 1997.

FONSECA, Claudia. Família, Fofoca e Honra: etnografia de relações de gênero e violência em grupos populares. Porto Alegre: Editora da Universidade Federal do Rio Grande do Sul, 2000, p. 7-51.

FONSECA, Claudia. Ser mulher, mãe e pobre. História das mulheres no Brasil, v. 9, p. 510-553, 1997.

PEDRO, Joana Maria. Traduzindo o debate: o uso da categoria gênero na pesquisa histórica. História (São Paulo), v. 24, n. 1, 2005.

PEDRO, Joana Maria. Mulheres do sul. História das mulheres no Brasil, v. 7, p. 278321, 1997.

PRITCHARD, Evans. Os Nuer: uma descrição do modo de subsistência e das instituições políticas de um povo nilota. São Paulo: Editora Perspectiva, 1999.

GARCIA JR, Alfrânio Raul. O Sul: Caminho do Roçado. São Paulo: Editora Marco Zero, 1990.

GIDDENS, Anthony. Sociologia. Tradução: Sandra Regina. 4a edição. Porto Alegre: Artmed, 2005. 


\section{Mulheres que "Botam Banca": Gênero e trabalho em Santarém/PA}

GODELIER, Maurice. Racionalidade e Irracionalidade na Economia. Rio de Janeiro: Tempo Brasileiro, 1969.

IBGE - instituto brasileiro de geografia e estatística. Censo demográfico. Rio de Janeiro: 2010.

NEVES, Delma P. Lavradores e Pequenos Produtores de Cana. Rio de Janeiro: Zahar Editora, 1981.

Niterói: Alternativa, 2013.

. Mulheres Camponesas: trabalho produtivo e engajamentos políticos. . Mulheres e mercado de trabalho: Aflições e conquistas. Mulheres em Santarém: Alternativa de vida (vol.I). Niterói: Editora alternativa, 2014.

REIS, Marla E. A. Relatório de Pesquisa de Iniciação cientifica. Santarém: Ufopa, 2013.

REIS, Marla E. A. Mulheres e a venda de comida em bairros periféricos de Santarém/PA. Santarém: Ufopa, 2016.

REIS, Marla E. A.; Wiggers, Raquel; NETO, Solon. P. G. "Só de ver a Gente Aprende": Uma Etnografia dos Saberes e Práticas Alimentares de Mulheres que vendem comida em Santarém/PA. Porto Alegre: Iluminuras, v. 20, n. 51, p. 227-247, dezembro, 2019.

SANTARÉM, Prefeitura municipal. Informações municipais. semplan/ciam, secretaria municipal de planejamento e coordenação geral. Setor de pesquisa e informações municipais, tânia mara moraes amazonas; núbia tavares de oliveira, 2009

SCOTT, Joan. Gênero: uma categoria útil de análise histórica. Educação e Realidade. Porto Alegre, v. 16 n.2, jul/dez 1990.

SENA, Ana Laura. O trabalho informal nas ruas e praças de Belém: um estudo sobre o comércio ambulante de produtos alimentícios. Belém: NAEA, 2002.

WEBER, Florence. Práticas econômicas e formas ordinárias de cálculo. Mana, v. 8, n. 2, p. 151-182, 2002.

Recebido 02/03/2020

Aprovado 10/04/2020 